\title{
II. Doppel-Lupengestell für Operations-Tubuslampen
}

W.

\author{
Reitsch
}

Hirschberg i. Rgb.

Heß hatte vor Jahren einen Stirnring mit vorgebauten Doppellupen angegeben, der bei kleinen Eingriffen in der Sprechstundenpraxis ein ausgezeichnetes Instrument zur Nah-beobachtung ist. Es hat den großen Vorteil, daß man voll-ständig freies Sehen in die Weite und Nähe hat, und daß zum scharfen Sehen in der Nähe eine ganz geringe Kopfneigung genügt, um mit Lupenvergrößerung arbeiten zu können. Ich möchte diesen 1/eßsch.en Ring nicht mehr entbehren. Für län-gere Operationen war er weniger bequem, vor allem war die Beleuchtungsvorrichtung nicht ideal. Ich habe darum für die vielgebrauchte Stirn-Tubuslampe (mit Kopf- oder Stirnspange) ein Doppellupengestell konstruiert, dessen Scharnier zwischen den Gläsern sitzt, so daß die Gläser dicht unter dem Tubus sich befinden. Diese Verbindung von gut leuchtender Stirnlampe mit vorgebauten Lupengläsern ziehe ich bei Operationen jeder Kombination mit Brille (ob Halb- oder Doppelfokusbrille) vor.

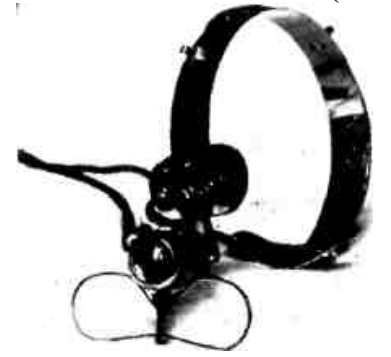

Die Herstellung des Doppellupengestells hat die Firma Frohnhäuser

München

Sonnenstraße

übernommen

die auch die $\mathrm{j}^{7} / 8^{1} / 8 /$ techen Stirnringe mit Doppellupen fabriziert. Es emp-fiehlt sich

etwa drei Gläserstärken (-(- 3

$-1-4$

-|- 5) zur Aus-wahl zu bestellen und bei der endgültigen Bestellung auch die eigene Refraktion mit berücksichtigen zu lassen. 